\title{
Incorporating Computer-Mediated Communication in Project Work
}

\author{
Faridah Musa $^{1}$, Maslawati Mohamed ${ }^{2}$, Norlaila Mufti ${ }^{1}$, Rozmel Abdul Latiff ${ }^{1} \&$ Maryam Mohamad Amin $^{1}$ \\ ${ }^{1}$ Pusat CITRA Universiti, Universiti Kebangsaan Malaysia, Bangi, Selangor, Malaysia \\ ${ }^{2}$ Faculty of Education, Universiti Kebangsaan Malaysia, Bangi, Selangor, Malaysia \\ Correspondence: Faridah Musa, Pusat CITRA Universiti, Universiti Kebangsaan Malaysia, 43600 UKM Bangi, \\ Selangor, Malaysia. Tel: 6-019-226-7754. E-mail: faridahm@ukm.edu.my
}

Received: July 23, 2014 Accepted: August 29, 2014 Online Published: April 28, 2015

doi:10.5539/ies.v8n5p150 URL: http://dx.doi.org/10.5539/ies.v8n5p150

\begin{abstract}
In line with the new trend of using computer-mediated communication (CMC) as an innovative technique in teaching and learning at higher institutions, Facebook as a channel of CMC was employed in carrying out a project work in an Academic Communication Course. For this project, students worked in groups to discuss their work and share information using both $\mathrm{CMC}$ and face-to-face interactions. An open ended questions survey was administered to these undergraduate students who were assigned to investigate a specific community issue involving a non-governmental organization (NGO) and to produce a report on the findings of the issue identified. This paper presents findings of an action research that aims to investigate the effectiveness of using CMC channel, Facebook, in the project work. It also aims to find out the challenges faced by students in using CMC. The content analysis of students' responses to the survey indicates the effectiveness of using CMC over face-to-face interactions in the completion of the project work despite the problems and challenges they faced.
\end{abstract}

Keywords: computer-mediated communication, Facebook, project work, face-to-face interaction

\section{Introduction}

\subsection{Overview}

Computer-mediated communication (CMC) is defined by Walther (1992) as "synchronous or asynchronous electronic mail and computer conferencing, by which senders encode in text messages that are relayed from senders' computers to receivers". In other words, communication between people in different places via the instrumentality of computers could take place synchronously (at the same time) and asynchronously (at delayed time). The rapid technological change has to some extent affects the instructional mode and communication in the classroom. The integrated use of technology offers numerous educational opportunities and possibilities when it is well-planned and implemented (D'Angelo \& Woosley, 2007). Language practitioners at higher institutions could adopt CMC in facilitating the process of learning. Lane (1994) stressed that in order to incorporate $\mathrm{CMC}$ in the classrooms educators need to understand that $\mathrm{CMC}$ is essentially a medium of written discourse. Lane also suggested that in order to partake in $\mathrm{CMC}$, one must have a minimum working knowledge of computer modems and communication software and be familiar with process of engaging in interpersonal CMC.

This study was embarked in an attempt to identify to what extent CMC channel, Facebook has benefitted the students. The objectives of this paper are twofold as listed in the following:

i. To investigate the effectiveness of using CMC in the project work.

ii. To identify the challenges faced by students in using CMC.

The findings of this study are important as such studies related to this area are still few in the Malaysian context. It is hoped that the findings of this study are able to provide helpful insights on how CMC could be utilized to facilitate students when carrying out project work.

\subsection{Problem Statement}

Academic Communication II is offered to first year undergraduate students in Universiti Kebangsaan Malaysia (UKM) who obtained MUET band score of 5 and 6. MUET is a Malaysian university entrance English proficiency test with Band 6 as the highest score. This course aims at enhancing students in utilizing critical 
thinking and communication skills through exposure to current and global issues. One of the course evaluations is project work which requires the students to work in groups of four to five to investigate a specific problem in a community involving a non-governmental organization (NGO). In carrying this project work, the students are instructed to utilize $\mathrm{CMC}$ to communicate with the group members and teacher. In this study, the CMC utilized by the students was Facebook.

This Project Work requires collaborative effort among the students. It is challenging as students have to meet outside the classroom constantly in order to plan, gather and analyze information related to the community problem they have chosen. They have to discuss the problem and choose appropriate research methods before carrying out field work by visiting a particular NGO. At the end of the project, students are required to write a project report based on the findings and also present them in a roundtable discussion. This project work is carried out on a learning contract approach, where students autonomously plan, select and implement appropriate strategies to achieve the learning outcomes of the project work. The teacher cum the researcher monitors the progress of the project via students' Facebook group by giving comments and responses while students are carrying out the project.

In order to complete the project, students are required to convene outside class hours regularly to ensure that they complete the project work within the stipulated time given. However, students with their tight schedule find face-to-face meetings demanding, exhausting and laborious. All these constraints may result in students losing their interest and enthusiasm, thus, affecting the quality of the completed task. Hence, exploring innovative and creative approach in motivating and sustaining students' process of learning outside the classroom is highly encouraged. CMC is incorporated in the teaching and learning at higher institutions to extend the boundaries of the classrooms to allow flexibility and innovation among students (DeSanctis \& Monge, 1999).

\subsection{Related Literature}

Straus and McGrath (1994) stated that face-to-face communication is superior to CMC, especially for highly interdependent tasks. Nevertheless, DeSanctis and Monge (1999) viewed that CMC is more effective than face-to-face communication for divergent tasks such as idea generation; while face-to-face communication is more effective for convergent tasks, such as decision making, which require interdependence on others.

Students preferred CMC mainly because it saves time and energy (An \& Frick, 2006). It allows more time to reflect and develop ideas. In addition, as claimed by these scholars, CMC offers students with more advantages over face-to-face communication. The advantages are as the following:

- It allows students to work around a flexible work schedule;

- It enables collaboration through communication over distance, to conduct research outside the classroom, and to generate diverse ideas in writing;

- It offers valuable opportunities for students who are shy in face-to-face discussion or are not fluent in English to engage in discussion more actively;

- It enhances students' ability to create and develop knowledge.

It is significant to note that CMC supports pedagogy but is not a replacement for face-to-face communication or instruction. CMC has its benefits that includes being interactive and global in nature. Reed (1998) emphasized that $\mathrm{CMC}$ allows students to navigate the direction of their learning and become more involved in their own education. He further stated that this is accomplished by equalizing the teacher-student time-ratio, by increasing opportunities to ask questions and analyzing the quality of messages. Erickson (1999) highlighted that CMC motivates learners and makes the instructors accessible to the students. Instructors use CMC as a platform to carry out discussion and forums for students to give opinions freely and conveniently. CMC promotes student-centred learning with wider students' participation at any time and place. It hinders students from being shy and apparently exposes students to opportunities to be creative and independent.

Over the years, the field of research on CMC has evolved due to the widespread of the Internet (Hratinski \& Keller, 2007). Globally, CMC promotes effective learning particularly among tertiary learners (Rusnani \& Russeni, 2006; Zaini \& Supyan, 2007). In recent years, many higher institutions in Malaysia have incorporated $\mathrm{CMC}$ as one of the learning platform in their language courses (Zaini \& Supyan, 2007; Maslawati, 2012). The language courses that incorporate a blended approach (a combination between face-to-face meetings and CMC activities) are still relatively new in Malaysia (Amelia \& Mohamed, 2007).

\subsection{Related Theories}

The review of theories related to $\mathrm{CMC}$, focuses on constructivist theories which could be divided into two: 
cognitive constructivist and socio-constructivist. This project work is based on cognitive constructivist theory as the students would become self-directed learners. They had to work individually to find and gather information about the relevant community and NGO in Malaysia. In doing so, they could further understand the nature of activities as well the challenges faced by similar community. For instance, a group of students selected a shelter home for abused women for their project. They searched via online about the selected shelter home to gain some information about it prior to conducting interview sessions and observations. The information would cover on the shelter home's history, objectives, mission and vision, activities, financial assistance and others. They would also search about shelter homes for abused women in Malaysia and other countries. By doing this, the students would develop better understanding of a shelter home for abused women which they shared with other group members through their Facebook group discussions. In writing reports, they did their work both individually and collectively via CMC. They discussed and tried to find possible solutions to the problems of the selected community for their project report. Evidently, this project work serves dual purposes-academic and social responsibilities.

The proponents of socio constructivist theory view that the environment or context plays an important role in language learning (Cole et al., 1978). These proponents opine that, "interaction with peers is essential as learning involves the people and the culture which surround the students. This view is one of the defining characteristics of the constructivist framework" (Tobias \& Duffy, 2009, p. 1). This constructivist and collaborative learning environments will create a better interdependence among students and better comprehension of the topic discussed.

Through group discussions and activities, the students started acquiring motivation, strategies, and positive attitudes which are significant to social participation. They participated in some voluntary work at the targeted NGO such as conducting singing and games activities with the community. This would help them to be more engaged with the community and promote better understanding through their involvement and observations. These activities enable the NGO to be more cooperative and open to give answers during the interview sessions. This project work enabled students to generate new ideas; gain knowledge and experience through reading, writing and speaking; and promote positive attitude with the assistance of their group members. When they worked in a group to achieve a shared goal upon completing the project work, they gave possible solutions and made decisions (Chapelle, 2003). They would also accept, discuss and debate the various suggestions given by the group members. They also supported, reflected and re-evaluated their suggestions and actions (Comeaux \& McKenna-Byington, 2003). Apparently, these activities could develop their creative and critical thinking skills in completing the task assigned in the project work.

\subsection{Related Studies}

There are few studies in Malaysian scenario that focused on the effectiveness of CMC in teaching and learning. Berhanuddin and Wan-Fara-Adlina (2004) studied online forum used in English as Second Language (ESL) classrooms. The interactions in the online forum were between engineering students from Universiti Tun Hussein Onn (UTHO) and Teaching English as Second Language (TESL) students from Universiti Teknologi Malaysia (UTM). They discovered that the learners cum participants of the online forum viewed 'Nicenet', as a favorite due to its simplicity and user-friendly features. The online forum was seen as a platform to use the target language in everyday settings. This allowed students to discuss academic issues and also developed casual interactions with the theme ranging from politics to entertainment.

Students were free to socialize with others regardless of their ethnic, religious and academic backgrounds. They also built social-cultural understanding through their discussions. Unlike face-to-face interactions which required impromptu feedback, asynchronous forum enabled the participants in the study to have time to think before posting their thoughts. The utmost limitation faced by the students was time. Students' busy learning schedule restricted them from indulging themselves in further reading and taking part in leisure discussions. Another limitation is the students' strong inferiority complex; they were afraid of making mistakes as they feared of being laughed at by all parties: their classmates, teachers and other participants.

A study carried out by Zaini and Supyan (2007) revealed the students' perceptions on the benefits of online forum. Most of their participants perceived that online forum allowed them to conduct discussions asynchronously. The students could proceed with their discussions without having to meet up via face-to-face. Their participants also responded that online forum allowed them to be more independent in their learning as this approach enabled them to obtain information through numerous websites in their own pace. Nevertheless, there are a few challenges faced by these participants. The biggest barriers are technical glitches which include low bandwidth which resulted in being disconnected during discussions, becoming lost in the system, and unclear 
voice of the instructors when interacting online.

Rusnani and Rosseni (2006) also stated similar notions in a study that involved 241 multiracial students from suburban areas. The study revealed that $\mathrm{CMC}$ is capable of promoting authentic communication as the users could interact among each other. Another advantage is the students have longer time to generate and organize ideas. They also had time to reflect their ideas, compose, revise and edit their own sentences for appropriate grammar, sentence structure and content worth before posting the sentences to the plenary.

The above three studies also highlighted that the students' comfort level depends on their familiarity and experience with technologies. Their findings also emphasized that those who have very limited knowledge in technologies particularly computer and Internet would feel uncomfortable with the new education system. The students need to possess the knowledge of using personal computer and to be familiar with the procedure for communication using CMC facility. They also need to have the ability to navigate through vast resources available in the Internet.

A study conducted by Bahar (2010) involving 32 undergraduates in Turkey who had enrolled in a 'Distance Education' course has shown that the students were getting more involved and became more frequent users of Facebook after the course. Some students viewed that Facebook has strengthened their communication with each other. $43.6 \%$ of these participants stated that they preferred a face-to-face course to a Facebook-based course. Most of the participants confessed that they could share their academic knowledge with their classmates in the Facebook. These findings indicated that a significant number of students believed that Facebook could be used as a platform for information sharing among students in academic contexts.

The literature discussed above shows the trend of using Facebook in language classrooms to promote authentic communication among participants. They focused on using Facebook as a channel of CMC for the purpose of carrying out discussions; where participants generate ideas, socialize, and communicate with others. However, the use of Facebook in a task-based work is still scarce in the local setting. This study looks into how participants use CMC as a platform to complete a task, which is the project work. On a micro level, participants' use of Facebook was analyzed in small groups.

\section{Methodology}

\subsection{Research Design}

An online survey using Google Doc was designed and administered to 13 students upon completion of the project work in Academic Communication II course. However, only eight responded to the online survey due to some technical problems in accessing the link to the survey. The survey was posted in the students' Facebook groups and within a week, two groups responded to the survey questions.

The survey consisted of seven open ended questions which participants answered individually at their own pace. The questions posted were on the effectiveness and challenges of the use of CMC as in Facebook in carrying out and completing the project work. The participants' responses were transcribed in verbatim.

\subsection{Subjects}

The 8 participants in this study were students from three different faculties-Faculty of Science and Technology, Faculty of Technology and Information Science and lastly from the Faculty of Economics and Management. They were Academic Communication II students who scored Band 5 and 6 in their MUET examination and are considered as highly proficient in English.

\subsection{Analysis of Data}

The responses in the open ended survey were analyzed and coded according to themes. The data was analyzed qualitatively to ensure depth in findings. Students' responses were labeled according to numbers.

\section{Results and Discussion}

This section discusses the effectiveness and challenges of using Facebook in carrying out the project work based on participants' responses of the open ended questions survey. The results agree with previous studies that Facebook facilitates discussion. It is interesting to note that Facebook also serves as a learning management system which provides a platform for students to complete a task-based project work. Participants verified that they used Facebook extensively to manage the project work as Facebook offers convenience, the ease of time management, information management, and lastly, group management. 


\subsection{The Effectiveness of CMC}

\subsubsection{Facilitating Discussion}

On the whole, most participants agreed that discussing their project on Facebook allowed them to expand their ideas. This finding is parallel with Bahar's (2010) study that Facebook could be used as a platform for information sharing among students in academic contexts. The participants also felt that Facebook is an effective means of communication because they could discuss with group members at any given time. Additionally, students also cited that it simplified their discussion as they were able to query the class teacher anytime they had doubts in their project work. Another reason why they felt that it simplified their discussion is because they did not have to waste time looking for venue for discussion. The following are some excerpts of the participants' narrative writing:

I was able to develop more ideas and expand them through the help of my group members. (S4)

Yes. It gave us a good platform to discuss our work among each other and with the instructor. (S5)

Allowed us to discuss the project without looking for a time when all of us could come and talk. (S6)

\subsubsection{Convenience}

The findings show that convenience was cited as the most common reason for using CMC. Participants felt that information sharing was made easy: they shared and expanded ideas; they went paperless; work was less stressful; and rich resources in the virtual world were just a click away. The following are excerpts from three participants:

Yes, because as popular as Facebook is today, most of us spend more than half of our time surfing through Facebook, therefore, we were able to share ideas and useful articles through the means that are convenient to us. (S4)

Yes, the process of learning had become less stressful with the aid of this informal tool. (S7)

Discussion around the clock; information sharing just a key tap away; paperless (print out only when necessary-go green!); can have face to face discussion too with video call/conferencing. (S8)

Other than the above three interviewees, all the participants felt that communicating through CMC-Facebook in particular, is especially convenient. This study highlighted that students find Facebook to be convenient because they are familiar with its interface. This social network is also a big part of students' lives. This is further affirmed by Patrcicio and Goncalves (2010) who did a study on Facebook in the learning process of university students in Spain. Their findings show that this social network is the most commonly used among university students worldwide to interact socially. They also discussed the advantages of Facebook towards students learning process. This includes participation in discussion groups which is a beneficial space to meet, share, brainstorm, and discuss ideas.

\subsubsection{Time Management}

Another emergent theme that was evident from the data gleaned was time management. Participants felt that their time was utilized efficiently when they worked collaboratively on Facebook. They felt that problems arising from their project could be attended to immediately and this sped up project work progress. Additionally, they also felt that they could work around the clock whenever they had free time to spend. The following are excerpts from two participants:

CMC can help to resolve the problems that the members couldn't find out a time when all of us can meet up. (S1)

Meanwhile CMC we can discuss anytime, anywhere and we are usually online. (S3)

These findings are in parallel with those of Zaini and Supyan's (2007) study. They found that online forum allowed the participants to work at any time convenient to them and at their own pace.

\subsubsection{Information Management}

Students felt that CMC allowed them a conducive platform for information management. It assisted them in several ways such as obtaining and sharing reference materials and collecting data as indicated in the following excerpts from three participants:

...more project-related information can be referred and sourced via CMC.(S4)

...through online research, we got a better view on the topic we did. (S6) 
...exposed more ways to collect data from the Internet. (S7)

They stated that CMC also assisted them in organizing the progress of their project work systematically as it helped them to keep track of their files. As their project work progressed, they were able to constantly update each other of the references they obtained individually instantly. This is seen from the following two excerpts:

...files are a lot easier to keep track of through CMC. This allows better organisation of the group and makes it easier to carry out the project. (S1)

...expedite the process of information sharing. (S8)

Another benefit of CMC is that it allowed them to brainstorm ideas together, and review their discussions in a more efficient manner as the discussion was recorded online. This is summed up from the following two excerpts:

... as the discussion goes on, all the group members are able to use the internet to find more facts to back up their own ideas or even get fresh new one. (S2)

...since whatever we discuss is online, I can look through it again and give out my view after reconsidering. (S3)

\subsubsection{Group Management}

Another benefit of CMC for group management is that it allowed the students to delegate work in a more efficient manner, enabled them to distribute tasks, set up appointments with each other, and also as a method of ensuring everyone in the group completes their part of the work. This is evidenced from one participant's comment in the following excerpt:

CMC assisted by facilitating the tasks assignations; appointments set-up; bandying ideas, findings; as a reminder for those who overlook/forgot their part. (S8)

The above findings show the application of Facebook as a learning management system whereby students felt that Facebook user interface allows them to navigate the contents easily. The findings of this study are similar with Maslawati et al. (2015) study. Her study highlighted that users prefer a website which is visual friendly. Visual friendly refers to the subheadings or subtopics which appear in the website interface. The users could always return to the main page even though they had opened up a few other subheadings. The subheadings are of different colors as to enable the users to differentiate between subheadings and paragraphs. Moreover, the paragraphs are not too lengthy and the font size is of moderate size. Facebook enables students to share resources, manage group discussions and .upload resources in the process of completing the project report.

\subsection{The Challenges of CMC}

Although CMC benefits in the implementation of project work among the group members, there are certain challenges that may restrict the success of the project work. Among the challenges faced by students are:

i. CMC does not provide optimum opportunities for effective group interaction as compared to face-to-face communication. They prefer face-to-face communication in improving interaction and developing verbal and non verbal communication. This is indicated in the following responses:

Face-to-face provides better group interaction compared to CMC. (S2)

...whereas face-to-face interactions provide the platform for better explanation and more effective discussions. (S5)

On the other hand, face-to-face interactions could improve one interpersonal skills, body language and non-verbal interpretation. (S6)

ii. CMC is perceived by some participants as not being able to facilitate or motivate their discussion. It merely provides a platform for communication purposes as shown below:

Not really. It was more of a communication medium than an ideas catalyst. (S3)

For me FB do not made me more motivated to participate in the discussion. (S4)

iii. CMC requires careful selection of words in expressing participants' thoughts considering they are from different social and academic backgrounds. This is reflected in the responses below:

Yes. Through CMC you have to be very clear in whatever you are trying to state. Therefore you have to be very precise with your words. Writing does not carry intonation so wording your thoughts carefully and clearly while taking into accounts the diversities of each group members. (S8) 
Careful selection of words are important to avoid annoying others' feelings in order to maintain participants' sense of belongingness especially with the absence of gestures and body language. The group members could resist others' ideas or withdraw from participating in the online discussion if they feel hurt and no longer perceived that they could connect with others in the group. In addition, asynchronous forum permits the participants to revise and refine their sentences multiple times before uploading the messages onto the plenary (Maslawati et al., 2014). Positive and frequent feedback from the teacher and group members could sustain collaborative work in elearning environment (Hisham \& Ruzhan, 2003; Maslawati et al., 2014).

The above data shows that $\mathrm{CMC}$ has its limitations. It is apparent that both $\mathrm{CMC}$ and face-to-face communication are interdependent in terms of equipping the students with effective interpersonal and communication skills in ensuring the success of group work. This supports Siti-Maliza et al. (2011) findings that the right blended learning which involved blended pedagogies with the combination of human interaction and computer interaction, tools and media needs to be created. Thus, CMC along with face to face interactions can be employed as it has enhanced students' learning in completing their project work.

\section{Conclusion}

This study highlights the benefits and the challenges of using CMC as a tool in facilitating project work in Academic Communication II course. CMC has assisted students in expanding their ideas, in utilizing time more efficiently, in working collaboratively via online, in accelarating work progress, and without the boundaries of time and space. Nevertheless, some students felt that face-to-face interaction is more effective when they need further clarification and justification of ideas. They also emphasized that face-to-face interaction could improve their interpersonal and non-verbal communication skills. This study has to a certain extent proven that Facebook is a favourable platform of communication among undergraduates in completing a project work. Through incorporating $\mathrm{CMC}$, the participants were actively engaged in performing the project after class hours, which indicates that Facebook was successful as a solution initiated by the instructor to optimize learning outside classroom walls. In addition, appropriate measures should be taken to minimize the arising problems faced by the students in using Facebook for the project work.

\section{References}

Amelia, A., \& Mohamed, A. E. (2007). Collaborative behaviours in a networked learning community: Initial findings. Internet Journal of e-Language Learning and Teaching, 4(2), 38-50.

An, Y.-J., \& Frick, T. (2006). Student perceptions of asynchronous computer-mediated communication in face-to-face courses. Journal of Computer-Mediated Communication, 11(2), 485-499. http://dx.doi.org/10.1111/j.1083-6101.2006.00023.x

Bahar, B. (2010). Facebook as a formal instructional environment. British Journal of Educational Technology, 41(6), 146-149. http://dx.doi.org/10.1111/j.1467-8535.2010.01115.x

Berhanuddin, M. S., \& Wan-Fara-Adlina, W. M. (2004). Participation in an online forum. Internet Journal of e-Language Learning and Teaching, 1(2), 33-47.

Chapelle, C. A. (2003). English language learning and technology. Amsterdam: John Benjamins Publishing Company. http://dx.doi.org/10.1075/1llt.7

Cole, M., John-Steiner, V., Scribner, S., \& Souberman, E. (Eds.). (1978). Vygotsky, L.S.: Mind in society: The development of higher psychological processes. Cambridge: Harvard University Press.

Comeaux, P., \& McKenna-Byington, E. (2003). Computer-mediated Communication in online and conventional classrooms: Some implications for instructional design and professional development programmes. Journal of Innovations in Education and Teaching International, 40(4), 348-355. http://dx.doi.org/10.1080/1470329032000128387

D'Angelo, \& Woosley (2007). Technology in the classroom: Friend or foe. Education, 127(4), 462-471. ProQuest Education Journals database.

DeSanctis, G., \& Monge, P. (1999). Introduction to the special issue: Communication processes for virtual organizations. Organization Science, 10(6), 693-703. http://dx.doi.org/10.1287/orsc.10.6.693

Erikson, T. (1999). Persistent conversation: An Introduction. Journal of Computer Mediated Communication, 4. http://dx.doi.org/10.1111/j.1083-6101.1999.tb00105.x

Hisham, D., \& Rozhan, M. I. (2003). Teacher-learner interactions in distance education: A case of two Malaysian Universities. Turkish Online Journal of Distance Education, 3(3). 
Hratinski, S., \& Keller, C. (2007). Computer-mediated Communication in Education: A review of recent research. Educational Media International, 44(1), 61-77. http://dx.doi.org/10.1080/09523980600922746

Lane, D. R. (1994). Computer-Mediated Communication in the Classroom: Asset or Liability? Workshop presented at the Interconnect '94 Teaching, Learning \& Technology Conference October 14, 1994

Maslawati, M. (2012). Hypermedia Reading Strategies of Adult Learners (Unpublished Ph.D. thesis). Universiti Kebangsaan Malaysia.

Maslawati, M., \& Shahizan, S. (2014). Online Forum Discussion to Promote Sense of Learning Community among the Group Members. International Education Studies Journal, 7(13), 61-75. http://dx.doi.org/10.5539/ies.v7n13p61

Maslawati, M., Harieza, H., \& Shahizan, S. (2015). Adult Learners' Perceptions of a Designed Hypermedia in a Blended Learning Course at a Public University in Malaysia. The Turkish Online Journal of Educational Technology, 14(1), 31-38

Murray, D. E. (2007). Creating a technology-rich English language learning environment. International Handbook of English Language Teaching, 49. Boston: Springer.

Patricio, M. R., \& Goncalve, V. (2010). Facebook in the Learning Process: A Case Study.

Proceedings of ICERI. (2010). Conference. $15^{\text {th }}-17^{\text {th }}$ November 2010, Madrid, Spain.

Reed, A. T. (1998). Online education: The Effect of Computer-mediated communication on tutor-tutee interactions (Doctoral dissertation, West Virginia University). Dissertation Abstracts International, 60-06a, AAG9926672.

Rusnani, A. K., \& Rosseni, D. (2006). Computer Mediated Communication. Jurnal Pendidikan, 31, 41-51.

Siti-Maliza, S., Suriani, J., Zubaidah, B., \& Kamaruzaman, J. (2011). Use of Information and Communication Technology in Enhancing Teaching and Learning. International Education Studies, 4(2), 153-156. http://dx.doi.org/10.5539/ies.v4n2p153

Straus, S. G., \& McGrath, J. E. (1994). Does the medium matter? The interaction of task type and technology on group performance and member reactions. Journal of Applied Psychology, 79(1), 87-97. http://dx.doi.org/10.1037/0021-9010.79.1.87

Tobias, S., \& Duffy, T. M. (2009). Constructivist instruction: Success or failure? New York: Routledge.

Walther, J. B. (1992). Interpersonal effects in computer-mediated interaction: A relational perspective. Communication Research, 19, 52-90. http://dx.doi.org/10.1177/009365092019001003

Zaini, A., \& Supyan, H. (2007). Students' perceptions of useful and challenging characteristics in an Online Learning Environment. In M. Rosniah, A. H. Bahiyah, \& M. L. Zalina (Eds.), Investigating Language: Research and Applications (pp. 61-80). Selangor: Universiti Kebangsaan Malaysia.

\section{Copyrights}

Copyright for this article is retained by the author(s), with first publication rights granted to the journal.

This is an open-access article distributed under the terms and conditions of the Creative Commons Attribution license (http://creativecommons.org/licenses/by/3.0/). 